\title{
Palliative Care Health Needs Assessment of Breast Cancer Patients Attending the Oncology Clinics of a Private Hospital in Southwest Nigeria
}

\section{Dr. Sarah Akande}

\section{Background}

\section{Results}

- Breast cancer remains the commonest malignancy affecting women in Nigeria.

- $\quad$ Like majority of cancers in Africa, it is diagnosed at an advanced stage when palliative care is often the only choice of treatment.

- The identification of the palliative care needs particular to each environment, can be a starting point in the development of a strategy for improvement of care and health service delivery.

\section{Pallative Care Needs of Patients}

60.00

50.00

\section{Method}

- The demographics, presenting complaints, diagnosis and palliative care needs of 46 participants and 35 family carers were assessed.

- $\quad$ The participants' ages ranged from 29 to 82 years. The largest proportion of participants were aged 61-70 years (28.3\%).

- Pain and physical symptoms were the highest palliative care needs of participants.

- The psychological and spiritual domains were the highest met needs.

- Information needs were the highest among the family carers.

40.00

30.00

20.00

10.00

0.00

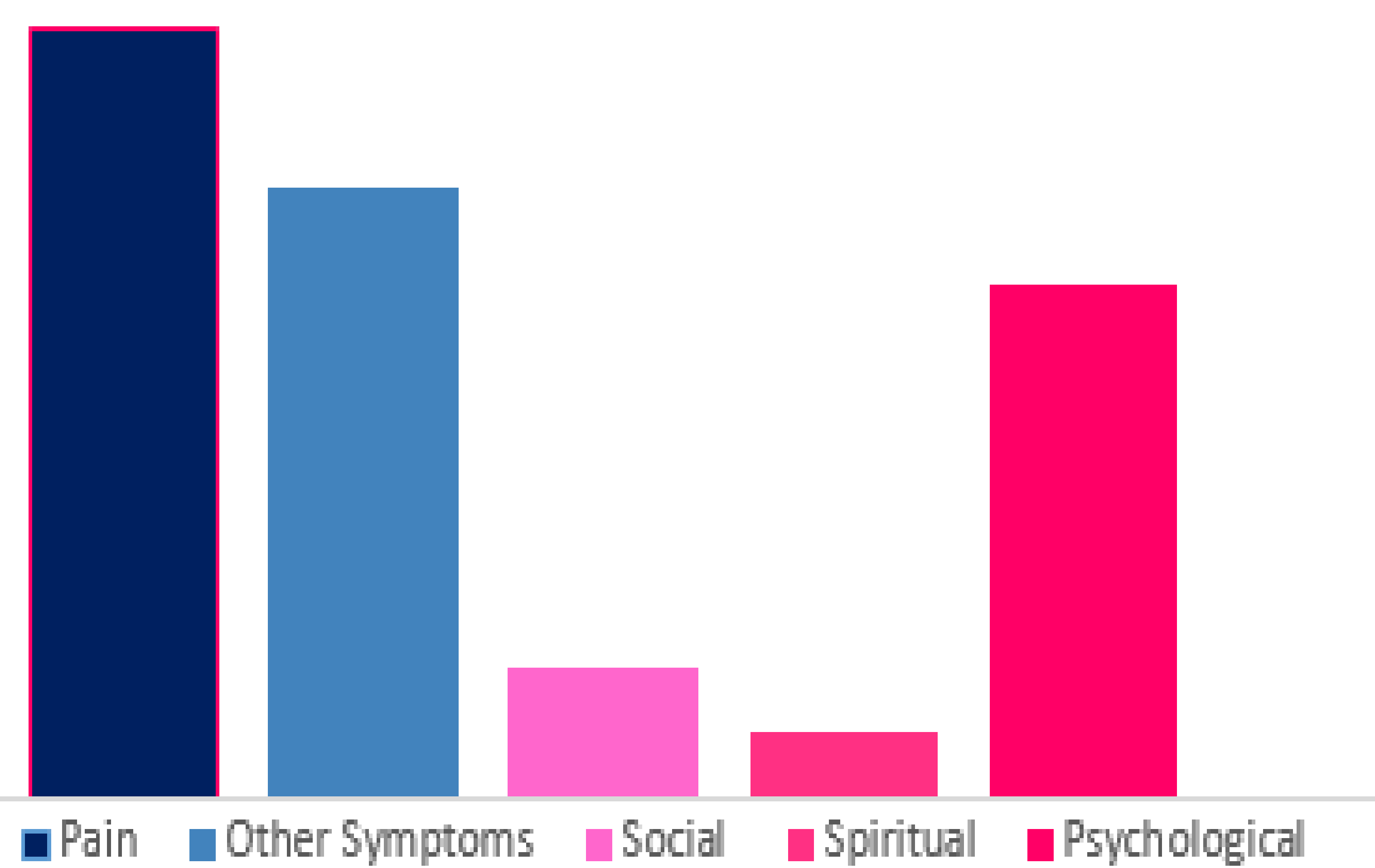

- The African Palliative Care Association (APCA) African Palliative Outcome Scale was used which contains 10 items, addressing the components of palliative care: physical, psychological, social and spiritual concerns, including the needs of both the patients and their family

\section{Conclusion}

- Palliative care is still nascent in Nigeria.

- These domains can be explored in the development of a structured palliative care programme. 